\title{
A visita técnica como método de ensino para guias de turismo: o Morro da Urca como local de visita e aprendizagem histórica
}

The Technical Visit as a Teaching Method for Tourism Guides: The Morro da Urca as Place of Visit and Historical Learning

José Lúcio Nascimento Júnior ${ }^{\star * *}$

RESUMO

$\mathrm{O}$ artigo parte das categorias produção de sentido, produção de presença e consciência histórica como referências para analisar um método de ensino de História no Curso Técnico em Guia de Turismo. Considerando que um professor, para ensinar, recorre a diferentes saberes, os quais possibilitam o uso de vários métodos, a escolha da visita técnica como ferramenta de ensino liga-se à possibilidade de junção de dois objetivos no ensino de História para futuros guias de turismo: a aprendizagem histórica e a experimentação do atrativo como local de visita e estudo.

Palavras-chave: ensino de História; turismo; patrimônio ambiental; patrimônio cultural.

\section{Abstract}

The paper takes the categories production of meaning, production of presence and historical awareness as references to analyze a method of teaching History in the Technical Course in Tourism Guide. Considering that a teacher, to teach, uses various knowledges which enable the use of different methods, the choice of the technical visit as a teaching tool is linked to the possibility of joining two objectives in teaching History for future tour guides: the historical learning and the experimentation of the attraction as a place of visit and study.

Keywords: history teaching; tourism; environmental patrimony; cultural heritage.

A circulação de pessoas sempre ocorreu ao longo da história da humanidade. Contudo, a prática do turismo conforme a conhecemos hoje tem sua historicidade, e seu início liga-se às transformações motivadas pela Revolução Industrial, a partir do século XVIII (Camargo, 2000). O desenvolvimento das

\footnotetext{
* Centro Universitário Augusto Motta (Unisuam), Faculdade de Arquitetura e Urbanismo, Rio de Janeiro, RJ, Brasil.

** C. E. Graciliano Ramos (Seeduc-RJ), Rio de Janeiro, RJ, Brasil. juniorhistoriador@gmail.com
} 
máquinas a vapor, mais especificamente da locomotiva e dos navios, e a invenção do telégrafo possibilitaram o deslocamento planejado de pessoas com objetivo de diversão e lazer. Na década de 1850 surgiu a primeira operadora de turismo, a agência de viagens Thomas Cook \& Son (Camargo, 2000; Boiteux; Werner, 2009).

O turismo como atividade socioeconômica surgiu no século XIX, mas foi nas últimas décadas do século XX que essa atividade ampliou significativamente sua abrangência de atuação. Novamente, as melhorias na infraestrutura de transporte e comunicação aliadas às transformações motivadas pela globalização e pelas Novas Tecnologias de Informação e Comunicação (NTIC) possibilitaram o conhecimento de novos lugares a se visitar. Atualmente, esse setor conta com a atuação de diferentes profissionais que, juntos, compõem o setor do turismo. Dentre eles destacam-se as agências de turismo (agências de viagens, operadoras e consolidadoras), as transportadoras (aéreas, terrestres e marítimas), e os guias de turismo (que podem estar vinculados a uma agência, mas não necessariamente).

O presente artigo focaliza os guias de turismo por ser com eles que, na maioria das vezes, os turistas têm mais contato, além de ser esse profissional o responsável por conduzi-los aos atrativos turísticos. Porém, não se analisará aqui a atuação profissional, mas seu itinerário formativo, considerando as contribuições do ensino de História nesse processo. Para tanto, visa-se demonstrar como a visita técnica pode ser um método de ensino de História que possibilita ao discente realizar uma aprendizagem histórica aliada a ferramentas necessárias à sua atuação profissional. Utiliza-se como estudo de caso a visita técnica ao Morro da Urca, no Rio de Janeiro, para demonstrar que diferentes saberes são mobilizados pelo professor de História que visa atuar no curso de Técnico em Guia de Turismo.

\section{O ENSINO DE História PARA GUIAS DE TURISMO}

O turismo costuma ser definido como "conjunto de técnicas baseadas em princípios científicos, as quais têm por objetivo prestar diferentes tipos de serviços às pessoas que utilizam seu tempo livre para viajar". Percebe-se, assim, que a atividade turística envolve deslocamento, hospedagem e lazer fora do ambiente rotineiro da pessoa. Dentre os serviços turísticos básicos 
encontramos: as agências de turismo, os meios de hospedagem e os guias de turismo (Boiteux; Werner, 2009).

O guia de turismo é o profissional que "além de prestar as informações necessárias, também acompanhará o turista e irá orientá-lo durante a viagem” (Chimenti; Tavares, 2007, p. 20). As atividades desenvolvidas por esse profissional podem ser divididas em quatro grupos: guiamento regional, excursão nacional, excursão internacional e guiamento especializado em atrativos naturais e culturais (Boiteux; Werner, 2009; Chimenti; Tavares, 2007). O conhecimento de história consiste, para ele, em uma ferramenta de trabalho que tem características próprias, e o historiador pode utilizá-las para produzir sentido e presença com sua aula, como se verá mais adiante.

Não cabe neste espaço fazer um levantamento exaustivo do significado de turismo, dos setores e profissionais a ele ligados, mas apresentar definições que auxiliam o professor de História a conduzir sua prática didática dentro e fora da sala de aula. Como destaca Valdei Araujo (2012), a aula pode ser um momento de produção de sentido de História, pois ela enquanto "acontecer de uma situação" permite ao docente (re)fazer "ligações do ser humano com o mundo". No caso da aula de história em um Curso Técnico em Guia de Turismo, tal situação pode acontecer dentro ou fora do espaço previsto e denominado "sala de aula", uma vez que a visita técnica, como variante do estudo do meio, coloca-se como uma possibilidade.

No caso da visita técnica, defende-se, com base nas propostas de Gumbrecht (2010), que ela propicia a produção de sentido e de presença. A presença tem um componente material, utiliza também uma referência espacial. Produzir presença consiste, portanto, em trazer para diante, estando à frente, ao alcance e tangível aos corpos (Gumbrecht, 2010). Desse modo, ao realizar uma visita técnica, o sentido de história produzido em sala pode materializar-se por meio de monumentos e atrativos observáveis, pois as escolhas demandaram uma interpretação e orientação tempo/espaço anterior àquele acontecimento (Rüsen, 2011).

Por isso, ressalta-se que tais produções, de sentido e de presença, não se fazem aleatoriamente. O mundo dos sentidos (e de sua produção) está ligado ao desenvolvimento da racionalidade moderna de base cartesiana. No momento atual, dada a saturação de sentido, a produção de presença é que se torna o grande desafio. No caso do professor de História que se dedica à 
docência em um curso de Turismo, especialmente no de guia de turismo, essa provocação pode contribuir com a aprendizagem histórica.

\section{A visita técnica como ferramenta metodológica}

Considerando que a forma de pensar Ciência ainda é influenciada pela noção construída na modernidade, cabe distinguir dois conceitos que fazem parte do cotidiano do professor: método e metodologia. O primeiro se refere a um caminho a ser seguido para se alcançar um fim, ao passo que o segundo indica o estudo desses caminhos (Haydt, 2006; Libâneo, 1994). Partindo dessa distinção, observa-se que a visita técnica consiste em um método de ensino: é um trabalho de campo que visa aproximar a prática profissional dos conhecimentos trabalhados em sala de aula.

A visita técnica é uma variação do estudo do meio proposto por Celestin Freinet. Para esse autor, era importante que os discentes conhecessem o local onde moram como forma de tornar mais próximo o conhecimento trabalhado em sala (Haudt, 2006). O estudo do meio como método de ensino de História já foi analisado como ferramenta para docência na educação básica (Guimarães, 2012).

A visita técnica é uma ferramenta didática que possibilita o trabalho interdisciplinar e o rompimento de visões estereotipadas sobre locais e processos históricos. Permite que o conhecimento histórico seja trabalhado sobre diferentes matrizes teórico-metodológicas, desenvolvendo o olhar a partir de domínios da própria História, tais como a História Cultural, a Social e a Ambiental, ou em diálogo com outras disciplinas, tais como a Geografia e a Biologia. Tais possibilidades ampliam o potencial dessa atividade como articuladora do fazer do professor de História em sala de aula, indo além dos muros da escola e (re)conhecendo o próprio local onde a escola está inserida e onde os estudantes vivem.

Selma Guimarães Fonseca destaca, ainda, que o estudo do meio como método de ensino

favorece o desenvolvimento de habilidades, sobretudo da capacidade de observação do estudante, num processo de investigação histórica que possibilita e requer a localização e a preservação de diversas fontes históricas. Nesse sentido, o estudo do meio não é um fim em si mesmo; não é, simplesmente uma excursão ou 
um passeio como alguns estudantes pensam. [...] [As] práticas educativas como o estudo do meio nos possibilitam "fugir às armadilhas", exige do professor uma relação crítica com as concepções de História recorrentes nos currículos e materiais. (Guimarães, 2012, p. 253)

A visita técnica, porém, tal como aqui se defende, parte de uma premissa diferente. Ela tem como objetivo propiciar ao estudante o conhecimento de alguns dos futuros locais de trabalho e simular uma prática. Tal configuração é adequada aos objetivos da educação técnico-profissional de nível médio, que abrange o curso de Técnico em Guia de Turismo. Ao contrário do estudo do meio que prevê a observação como ferramenta, a visita técnica possibilita que os três componentes da aprendizagem histórica sejam trabalhados: a observação, a interpretação e a experiência (Rüsen, 2011), e neles se baseia para a formação profissional.

Outra questão relevante é o fato de esse método possibilitar que o professor de História, em sua aula, produza sentido e presença (Gumbrecht, 2010). Como propõe Valdei Araujo com base nas formulações de Hans Gumbrecht, a aula de História pode produzir sentido e presença, sendo narrativa e evento. A aula não deve apenas buscar sentido no passado, mas produzi-lo tomando por base o presente (Araujo, 2012). Desse modo, vê-se que a visita técnica permite produzir sentido e presença por meio da visitação a ambientes escolhidos pelo docente, sendo esses locais não necessariamente já reconhecidos como de interesse histórico.

Para vários estudiosos, a partir da década de 1970 a experiência do tempo se modificou. Hartog (2014) afirma que vivemos hoje no presentismo, momento em que o presente se alarga, formando um contínuo com o passado e o futuro, sendo que o interesse por ele também se torna maior. Esse alargamento, por sua vez, foi responsável pela mudança: (1) na percepção do tempo (Araujo, 2012); e (2) na forma como as pessoas passaram a lidar com o passado, em especial com o surgimento de novos patrimônios e de sua visitação (Hartog, 2014). No conjunto dessas transformações houve a expansão da atividade turística, o que gerou o aumento da demanda por profissionais de turismo, em especial do guia de turismo.

Retomando a questão da visita técnica, não se pode deixar de sublinhar que existem outras experiências de didática da História que utilizaram a 
estratégia da visitação a partir de práticas de estudo do meio. Por exemplo, no Colégio de Aplicação da Universidade do Estado do Rio de Janeiro (CAPUerj), Menezes e Silva (2007) utilizaram a visitação como forma de educar o olhar, ou seja, como ferramenta para discutir com suas turmas do Ensino Fundamental das Séries Iniciais questões relativas a memória e identidade a partir da observação dos locais onde os estudantes moravam e transitavam para ir à escola. Como parte da formação de estudantes nesse segmento de ensino tal estratégia possibilita a ampliação do olhar sobre onde se mora e sobre a relação desse local com a história do país.

Ao analisarem a didática e o ensino de História na Educação Básica, Almeida e Vasconcellos (2013), Schmidt e Cainelli (2009), Guimarães (2012) e Oriá (2013) destacam a importância de se trabalhar a história local, a memória e a visitação como ferramentas que o professor pode utilizar em suas aulas. Essa indicação não parte de um levantamento exaustivo, mas demonstra que a questão de extrapolar os muros das escolas vem ganhando força como ferramenta para o ensino de História, o que não se pode deixar de considerar como modificação na forma de pensar a aula. Esta deixa de ser um momento apenas de produção de sentido, proporcionando, também, a produção de presença.

De acordo com Schmidt e Cainelli (2009, p. 153), "é no cotidiano das cidades que se apresenta a possibilidade de ensinar a leitura do mundo a partir das representações construídas, como patrimônios e monumentos". Enquanto campos do saber, a História e o Turismo pensam os patrimônios e monumentos com base em características diferentes. Para o segundo, o atrativo é um produto a ser comercializado; para o primeiro, ele apresenta e representa o desenvolvimento histórico e sociocultural de um grupo social ou localidade (Meneses, 2006). Cabe ao professor de História que atua na formação do guia de turismo trabalhar para que a visão mercadológica seja superada pela consideração dos valores históricos e/ou patrimoniais, o que não siginifca dizer que a relação de mercado irá desaparecer da atuação, mas que ela irá ceder lugar a práticas orientadas de aprendizagem da cultura histórica do local.

A aprendizagem histórica acontece em diferentes locais, e muitas vezes a história local acaba sendo algo mais próximo do professor e do estudante, pois sua presença pode ser percebida de diferentes formas. Como exemplo de método de estudo da história local que pode resultar tanto em um estudo do meio 
quanto em uma visita técnica, o professor pode propor o estudo da história local partindo dos nomes das ruas e praças (Guimarães, 2012). Nesse sentido, o que diferencia o estudo do meio da visita técnica?

Em nossa perspectiva, a ênfase: no primeiro, o local é tomado como objeto de estudo buscando ampliar o conhecimento sobre ele; no segundo, o local ao mesmo tempo é objeto de estudo e é utilizado com espaço de formação profissional, onde o discente utiliza-se de técnicas adquiridas em sua formação para simular sua prática. Lecionando em um Curso Técnico em Guia de Turismo, pode-se utilizar a visita técnica para a visitação e a observação das fachadas dos edifícios e casas e/ou de possíveis atrativos que poderão compor futuros roteiros e pacotes turísticos a serem comercializados a grupos de turistas.

Outro exemplo de estudo de história local que resoltou em boas práticas de visitação foi desenvolvido por Ricardo Oriá no projeto "Conhecer para preservar - Preservar para Conhecer: Fortaleza, os lugares de memória”, junto aos discentes de Prática de Ensino da Universidade Federal do Ceará (UFCE). O autor assim resumiu a prática desenvolvida ao longo do projeto:

Os estudantes foram levados a pesquisar e mapear os bens histórico-culturais da cidade, especialmente os imóveis, destacando os seguintes aspectos: em que estado físico se encontravam, sua condição jurídica (bem tombado ou não, integra ou não área de proteção ambiental, possui legislação específica de proteção etc.) e o atual uso social dado ao mesmo. A partir disso, foram elaborados roteiros destinados às escolas, para que pudessem viabilizar visitas monitoradas aos bens culturais da cidade.

Posteriormente, sentimos a necessidade de incorporar esses roteiros à prática efetiva da sala de aula, através da introdução de um capítulo de livro sobre a História de Fortaleza e seus lugares de memória, durante a elaboração do livro, já citado, Fortaleza: a criança e a cidade, destinado às series iniciais do ensino fundamental. (Oriá, 2013, p. 144-145)

Projetos como o desenvolvido por Oriá (2013) possibilitam a superação de uma formação inicial fragmentada e desconectada com a prática docente. Apesar de os cursos de História surgidos na década de 1930, na Universidade de São Paulo (USP) e na Universidade do Distrito Federal (UDF), atual Universidade Federal do Rio de Janeiro (UFRJ), terem por objeto a formação 
de professores de História, ao longo da segunda metade do século XX, aos poucos e de forma silenciosa, a universidade foi se distanciando da escola, o que trouxe prejuízos para ambos os segmentos da educação escolar. Mas o Encontro "Perspectivas do Ensino de História", realizado pela primeira vez em 1988, pode ser visto como um marco na tentativa de reaproximação entre escola e universidade, pelo menos no que compete ao ensino de História (Guimarães, 2012).

Com base no que foi aqui exposto, a visita técnica prevê algumas etapas para sua realização: seleção do lugar a ser visitado, planejamento da ação a ser realizada e avaliação dos objetivos propostos (Menezes; Silva, 2007). Tal técnica possibilita o (re)conhecimento de locais importantes no bairro ou na cidade, partindo da memória coletiva para o conhecimento histórico mais sistematizado (Gonçalves, 2007; Menezes; Silva, 2007). Tal prática constitui uma ferramenta que possibilita ao docente propor situações de aprendizagem próximas, ou não, à vivência dos futuros guias de turismo.

Como se viu, o guia de turismo pode atuar com guiamento regional, excursão nacional e internacional, e guiamento especializado em atrativos naturais e culturais. Pondera-se, por exemplo, que o professor de História esteja ministrando um curso de Patrimônio Histórico-Cultural e tenha escolhido o Morro da Urca, no Rio de Janeiro, como local a ser visitado. Nele é possível desenvolver diferentes formas de visitação turística a serem exploradas de várias formas em aulas de História. Apresenta-se, a seguir, a aplicação dessas etapas.

\section{ApliCAÇÃo Do MÉTODO}

\section{O lugar}

Situado na Urca, bairro tradicional da Zona Sul da cidade do Rio de Janeiro, o Morro da Urca faz parte do complexo geológico do Pão de Açúcar. Orograficamente, o morro faz parte da Serra da Tijuca, compondo junto com o Pão de Açúcar um dos principais cartões-postais da cidade, tendo sido tombado pelo governo federal em 1973 (Lyra, 2006). Situa-se na entrada da Baía de Guanabara, à beira-mar, em especial junto à praia Vermelha, e tem vegetação de restinga (Lyra, 2006). 
Com o início do processo de conquista e ocupação europeia no século XVI, o Morro da Urca era uma das regiões onde ocorriam os conflitos entre portugueses e franceses pelo domínio da região. Os franceses liderados por Villegaignon buscaram o apoio dos índios Tamoios para se fixarem na região. Tal situação apenas mudaria na década de 1560, quando expedições organizadas por Mem de Sá, em 1560, e por Estácio de Sá, em 1563, entraram em conflito com os franceses e os expulsaram do litoral. A fundação da cidade do Rio de Janeiro em $1^{\circ}$ de março de 1565 está ligada ao fim desse conflito (Wehling; Wehling, 1994).

No século XIX esse era um local pouco visitado. Existem relatos de práticas de escaladas, desde 1817, tanto no Morro da Urca quanto no Pão de Açúcar, mas os dois atrativos apenas apareceriam nos guias turísticos ${ }^{1}$ após 1912, quando foram inaugurados os teleféricos (Perrotta, 2013). Essa inauguração impulsionou o turismo na região, pois o Complexo do Pão de Açúcar se tornaria um dos cartões-postais da cidade do Rio de Janeiro e um de seus atrativos mais conhecidos no Brasil e no mundo.

Figura 1 - Mapa da Cidade do Rio de Janeiro

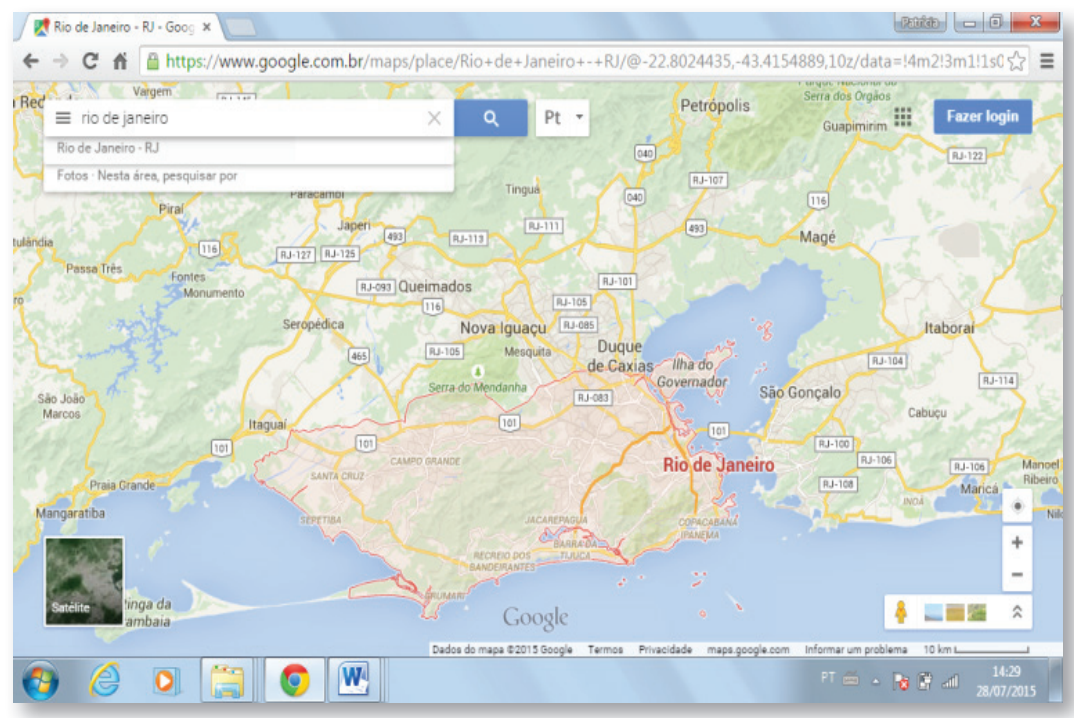

Fonte: imagem disponível em: https://www.google.com.br/maps/place/Rio+de+ Janeiro+-+RJ/@-22.8024435,-43.4154889,10z/data=!4m2!3m1!1s0x9bde559108a05b :0x50dc426c672fd24e. Acesso em: 28 jul. 2015. 
Figura 2 - Monumento Natural dos Morros do Pão de Açúcar e da Urca.

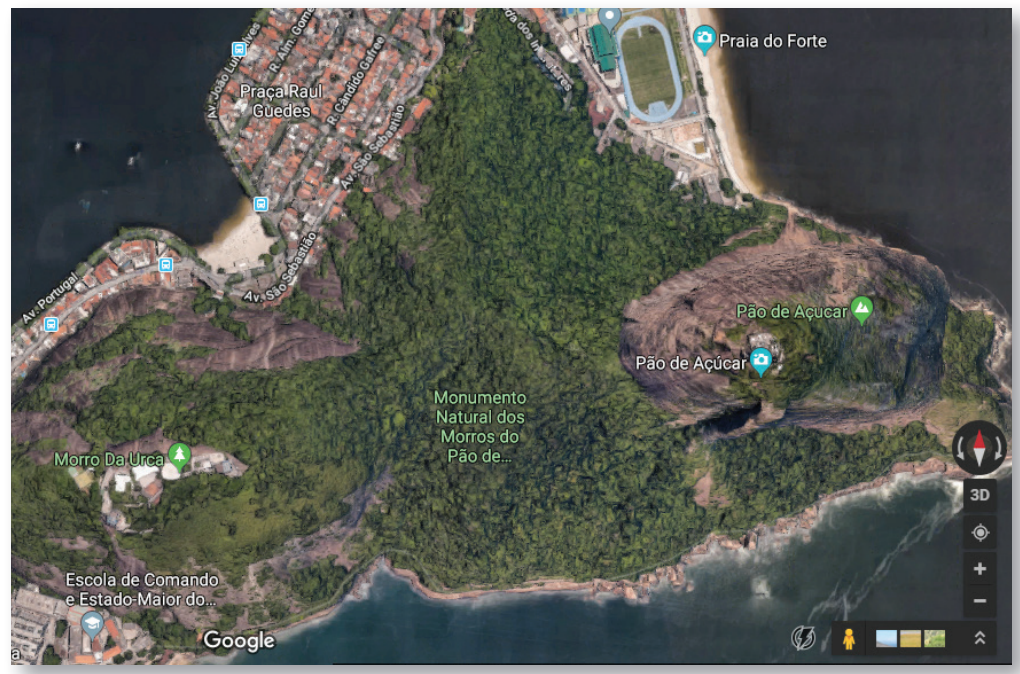

Fonte: imagem disponível em: https://www.google.com.br/maps/place/ Urca,+Rio+de+ Janeiro+-+RJ/@-22.9489565,-43.1610735,16.04z/data=!4m5!3m4! 1s0x998041d0e63547:0xacf22f89465ebf46!8m2!3d-22.954378!4d-43.1675881. Acesso em: 28 jul. 2015.

Na Figura 2, percebe-se que tanto o Morro da Urca como o Pão de Açúcar são próximos, fazem parte do mesmo Monumento Natural e têm como características comuns as encostas abruptas, que permitem a realização de escaladas e outras atividades turísticas. Caso se pense a história da ocupação do lugar, outras atividades podem ser sugeridas, tais como a visita a monumentos presentes na Praia Vermelha. Além disso, o Morro da Urca é utilizado como local para ecoturismo e prática de esportes. Existe uma trilha (Figura 3) que possibilita ao visitante subir o Morro, podendo seguir de bondinho até o Pão de Açúcar ou descer, aproveitando a vista que o teleférico oferece do litoral. Ainda existe a possibilidade de se praticar esportes na pista Claudio Coutinho, localizada em sua base.

Para Carvalho e Costa (2016, p. 60), "um grande desafio, portanto, é inserir de forma crítica e construtiva a natureza nas aulas de História”. $\mathrm{Na}$ Educação Básica esse desafio está posto e deve ser enfrentado; na formação de guias de turismo, o professor de História tem outras formas de enfrentar a questão. Superar o silenciamento da natureza na História - seja nos livros 
didáticos, seja em uma história de penitência, na qual a natureza é vista como vítima do capitalismo - pode ser uma tarefa de quem atua nos cursos de formação de guia de turismo, pois a natureza - ou melhor, o ambiente natural também é atrativo a ser visitado pelo turista.

Uma das possibilidades de superar a dicotomia estabelecida ao longo da modernidade entre ser humano e natureza consiste em pensá-la com base na definição de patrimônio cultural exposta no Decreto-Lei 25 de 1937, que definiu as bases do Patrimônio Artístico e Histórico Nacional, no decurso do governo Vargas (1930-1945). Segundo esse decreto, os monumentos naturais, sítios e paisagens equiparam-se aos bens móveis e imóveis de interesse histórico, artístico e arqueológico a serem conservados.

A Educação Patrimonial em cursos de Turismo deve, portanto, considerar a contribuição da História Ambiental para a problematização da relação entre o ser humano e a natureza. Isso porque a própria história do turismo moderno se iniciou com a busca de locais afastados dos centros urbanos e que tivessem belas paisagens a serem contempladas.

Não cabe neste espaço analisar a visão da natureza ao longo do século XIX e a influência do Romantismo nessa visão - ou a visão de natureza existente no Brasil na década de 1930, quando da promulgação do Decreto-Lei 25/1937. Porém, não se pode deixar de destacar que a beleza natural do Brasil, em geral, e do Rio de Janeiro, em particular, chamou a atenção de viajantes desde o século XVI, e de turistas desde o século XIX, figurando, na atualidade, como um dos motes para a atração - tendo em vista que algumas dentre as cidades brasileiras mais visitadas se destacam pelos seus atrativos naturais (Boiteux; Werner, 2009).

\section{As atividades a serem desenvolvidas}

Considerando os três componentes da aprendizagem histórica, tais como proposto por Rüsen (2011), o desenvolvimento das atividades inicia-se pela orientação. Antes da visita, realizam-se aulas em sala acerca dos aspectos históricos dos principais atrativos turísticos da cidade. Ao longo dessa parte teórica, dialoga-se com outras áreas do conhecimento que são importantes para a formação do guia de turismo, tais como a História da Arte e da Arquitetura e a Geografia. Tomam-se as transformações históricas do Rio de Janeiro como 
fio condutor para produzir sentido e orientação. Como forma de observação e experiência, ou seja, para a produção de presença, utiliza-se a vista técnica ao Morro da Urca.

Os momentos em sala são importantes para auxiliar na orientação e interpretação histórica que se deseja alcançar, ou seja, na produção de sentido buscada pelo docente. Mas a visita técnica como momento em que se traz para diante de si a materialidade do que se está estudando consiste em uma eventividade diferente da sala de aula, onde "podemos apontar a presença de determinados objetos e convidar os alunos à serenidade, isto é, a estarem ao mesmo tempo concentrados e disponíveis, sem deixarem que a concentração calcifique a tensão de um esforço" (Gumbrecht, 2010, p. 132). Ambos os momentos são importantes para a aprendizagem histórica, mas reúnem características diferentes.

Para a visita técnica, agrupam-se os estudantes em equipes que irão apresentar aos colegas alguns dos artefatos que compõe o atrativo escolhido. Tendo como ponto de encontro o monumento aos Heróis de Laguna, na praça General Tibúrcio, situada na Praia Vermelha, é possível iniciar ali os processos de observação e a experiência, pois esse pode ser o primeiro atrativo a ser trabalho na própria visita técnica. Além do monumento citado, na Praia Vermelha é possível observar as estátuas do compositor Frédéric Chopin e das deusas romanas Ceres, Pomona, Floral e Vesta, simbolizando as quatro estações. Localiza-se ali, também, o Instituto Militar de Engenharia. O primeiro grupo, assim, ficaria responsável por esse primeiro conjunto de atrativos.

Esses atrativos possibilitam ao professor de História o diálogo com diferentes temporalidades, pois nesse tipo de visitação os monumentos costumam remeter a diferentes eventos. O monumento aos Heróis de Laguna se mostra como oportunidade para se trabalhar a Guerra do Paraguai. O monumento visa trazer à memória a retirada do Exército brasileiro do território paraguaio, após a investida sem sucesso comandada pelo coronel Carlos de Morais Camisão, em julho de 1868. Da tropa de 3 mil homens, apenas 700 retornaram. Mas o monumento também pode ser analisado no contexto do desenvolvimento da estatutária no Brasil. Idealizada na década de 1920, a construção da escultura aos Heróis de Laguna e Dourados utilizou canhões da época da Guerra do Paraguai, ocorrida meio século antes. A guerra ficou eternizada não 
apenas na homenagem que o monumento faz a ela, mas também nos materiais utilizados para a sua construção (Ramos, 2014).

Ao longo do século XIX, em especial após a implantação da Academia Imperial de Belas Artes, com apoio da Missão Artística Francesa, houve no Brasil o desenvolvimento do uso de estatutária, mas a República também se valeu do recurso para a promoção de uma pedagogia cívica (Knauss, 2000). No caso desse monumento, a escultura visa apresentar uma narrativa - sua configuração faz a mediação de sentido, proporcionando ao espectador uma leitura do evento representado.

Outra estátua em bronze citada é a do compositor e pianista Frédéric Chopin (1810-1849), também localizada na praça General Tibúrcio. Inaugurada nos anos 1940, sua idealização seria uma crítica à invasão da Polônia pelos exércitos nazistas e estaria ligada, também, à comemoração do centenário da morte do artista. A estátua, antes de se instalar definitivamente nessa praça (nos anos 1960), esteve na entrada do Theatro Municipal do Rio de Janeiro, na Cinelândia, de onde foi retirada após protestos - defendia-se que na entrada do teatro deveria haver um artista brasileiro e não estrangeiro.

Tratando ainda das estátuas presentes na praça General Tibúrcio, é preciso citar as deusas romanas Ceres, Pomona, Floral e Vesta, construídas em mármore e distribuídas pela praça. O uso de estátuas de deusas greco-romanas como parte da ornamentação de praças e construções no Brasil remete à influência neoclássica e às suas transformações a partir do século XIX. Existe um sem-número de construções na cidade que utilizaram esse recurso como parte de seu ornamento e ainda são passíveis de visitação.

A presença desses monumentos torna-se o fio condutor para a construção da narrativa histórico-cultural que o estudante do Curso de Guia de Turismo irá utilizar para simular a condução de grupos. Ao observarem os elementos e os apresentarem aos colegas da turma (ou seja, demonstrar sua interpretação enquanto experimentam a vivência do guiamento), poderão utilizar os três elementos da aprendizagem histórica, tais como proposto por Rüsen: a observação, a interpretação e a experiência. Pois, como adverte o próprio Rüsen (2011, p. 80), "a consciência histórica vem à tona ao contar narrativas, isto é, histórias, que são uma forma coerente de comunicação, pois se referem à identidade histórica de ambos: comunicador e receptor". Tal possibilidade se estende pelo conjunto da atividade proposta. 
Após a observação dessas estátuas, o grupo segue para a Pista Claudio Coutinho, localizada no Monumento Natural dos Morros da Urca e do Pão de Açúcar, onde se situa o segundo grupo de atrativos. Depois de uma caminhada na Pista, esse grupo de estudantes conhecerá um exemplo de patrimônio natural, local onde uma unidade de conservação é utilizada de forma a integrar observação da natureza e espaço de lazer e de atividades de turismo e meio ambiente, uma vez que no Morro da Urca existem uma trilha - que se inicia na Pista Claudio Coutinho - e locais para escalada. O grupo poderá experimentar e observar in loco como o guiamento em atrativo natural pode ser ampliado por um olhar histórico.

Figura 3 - Trecho da trilha no Morro da Urca.

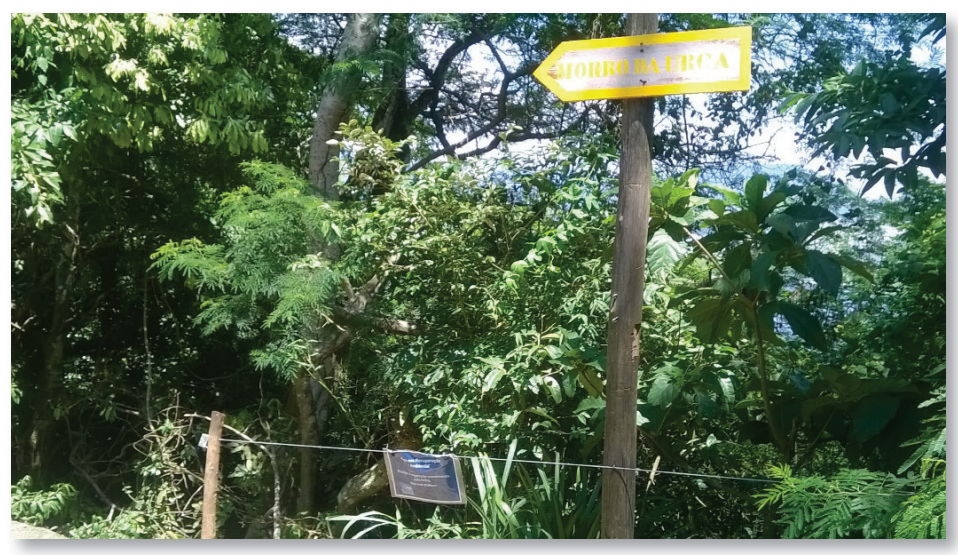

Fonte: Acervo pessoal do autor.

E por que inserir na aula de História a observação de elementos naturais? Para Oriá (2013, p. 141), "a grande maioria dos programas de educação ambiental têm sido omissos no tocante à dimensão cultural do meio ambiente, no que se inclui, necessariamente, a discussão relativa à preservação do patrimônio histórico". Não que as aulas de História sejam a panaceia que irá resolver todas as questões socio-educacionais, mas em seu planejamento o professor pode aproveitar a visita técnica, como neste caso, para também tratar dessa questão.

Ao caminhar pela Pista Claudio Coutinho, o professor e sua turma se encontram próximo a um elemento cujo nome remete a uma das principais 
atividades econômicas do período colonial: a produção de açúcar. Acrescenta-se o fato de o Decreto-Lei 25/1937 equiparar os monumentos naturais ao patrimônio histórico cultural. Além disso, não se pode deixar de sublinhar que são as belezas naturais um dos principais elementos que colocam o Rio de Janeiro (e o Brasil) como alvo da atividade turística. Esse pode ser o pontapé inicial para a inserção da questão ambiental na atividade que se está desenvolvendo.

Seguindo o tema do tombamento, o professor de História pode demonstrar como o Decreto-Lei 25/1937 está sendo efetivado, pois esse Monumento Natural conta com tombamento federal (Processo 869-T/1973, com inscrições $\mathrm{n}^{\circ}$ 52, 53, 54 e 58 no Livro Arqueológico, Etnográfico e Paisagístico) e com tombamento municipal de acordo com o Decreto 26.578, de $1^{\circ}$ de junho de 2006. O tombamento federal agrupa em um mesmo livro os momentos Arqueológicos, Etnográficos e Paisagísticos, de modo que o professor de História, ao propor visitas técnicas, pode e deve considerar elementos não apenas culturais, mas também ambientais.

Caso se escolha seguir pelo nome do atrativo, o Pão de Açúcar se localiza na entrada da Baía de Guanabara, como se pode ver no mapa apresentado na Figura 1. A escolha desse nome se deu por sua proximidade visual com os blocos de açúcar transportados nos navios que cruzavam o Atlântico, antes mesmo da chegada dos portugueses. Somado a isso, o morro se tornou referência para os navegadores que visavam chegar às terras do Rio de Janeiro, no recôncavo da Guanabara.

O conhecimento pela presença passa pelos sentidos, tal como aponta Gumbrecht (2010), o que nos leva a defender que, ao realizar a segunda etapa da atividade, o professor de História demonstre como era a visão que se tinha da cidade a partir do Monumento Natural do Morro da Urca e do Pão de Açúcar, apresentando as transformações na cidade que daí se pode observar, seja de sua parte mais baixa (enquanto se caminha pela Pista Claudio Coutinho), seja do alto do Morro, após a trilha. Tal movimento nos leva ao final da visita técnica.

A atividade se encerra no Morro da Urca, onde o terceiro grupo poderá se valer: (1) de elementos museais que existem no local para demonstrar como foi a história de construção e utilização do bondinho; e (2) da visualização de parte do centro da cidade, apresentando alguns dos atrativos turísticos lá 
existentes. A utilização do espaço do museu como local de aprendizagem histórica liga-se a dois fatores: (i) "a popularidade sem precedentes e os novos estilos de exposição dos nossos museus" no momento atual (Gumbrecht, 2010, p. 151); e (ii) o crescimento no número de atrativos considerados patrimônio, que levou ao abuso no seu uso (Hartog, 2006). A visualização da cidade pode levar os estudantes a observarem as permanências e ausências que marcam a sua transformação ao longo do tempo.

Para finalizar a atividade, propõem-se como opções de descida que se (i) retorne pela trilha ou (ii) utilize o bondinho. Isso porque existem grupos de turistas que irão visitar esse monumento natural e terão apenas a experiência de conhecê-lo (observação e experiência a partir da produção de presença) pelo que o bondinho pode demonstrar.

\section{A avaliação da atividade}

A avaliação da atividade acontece em dois momentos distintos e interligados. Primeiramente, ao fim da visita, quando os discentes poderão relatar como foi a experiência da visitação; esse momento destina-se à troca de experiências, do que cada um vivenciou com a visita, e de informações pertinentes, pois alguns detalhes da explanação podem ter escapado durante a visitação. Nesse momento o docente poderá observar como está ocorrendo a relação do discente com os atrativos visitados e, se necessário, propor novas abordagens. Pois, como defende Rüsen (2011), é a partir de experiência do presente do estudante que se pode colocar em prática o aprendizado histórico.

Ao comentar o roteiro realizado, abre-se também a possibilidade de inserção de novos atrativos em uma visitação posterior. O olhar lançado para esse espaço da cidade pode despertar o interesse para outros espaços e, dessa forma, construir novas leituras sobre a cidade e sobre a atuação do guia de turismo, que se afastem daquelas ligadas apenas aos atrativos ligados aos roteiros já estabelecidos. Dessa forma, a aprendizagem histórica pode desenvolver uma nova relação dos discentes com o passado e com a cidade.

O segundo momento de avaliação consiste na apresentação, em aula posterior, de um pacote turístico desenvolvido a partir da visitação. Como o aprendizado histórico é o processo de perceber o passado no presente, e os discentes experimentaram a visitação a esse conjunto de monumentos e viram como estes 
compõem um produto turístico, é possível verificar como interpretam o passado e o presente na construção de um roteiro que foi experimentado. Podem, também, partir dessa experiência para construir novos roteiros. Assim, o sentido produzido pela presença pode ser demonstrado e compartilhado com os demais discentes, além de favorecer novas leituras possíveis da cidade.

\section{CONSIDERAÇÕES FINAIS}

A visita técnica como ferramenta didática do professor de História que leciona em Curso Técnico em Guia de Turismo é recurso que possibilita, ao mesmo tempo, proporcionar aos estudantes: (i) a experimentação de um atrativo turístico, e (ii) novas formas de aprendizagem histórica que vão além do sentido produzido em aula. A visita promove outra forma de se pensar o ensino de História, voltado para questões pertinentes tanto ao campo da História quanto à formação profissional do estudante de turismo.

O presente artigo, nesse sentido, pretendeu demonstrar a importância da reflexão do professor de História sobre o seu público alvo ao escolher um método didático. A escolha não se pode realizar apenas com base nas questões do campo da História, uma vez que visa contribuir com a formação profissional de um agente de outro campo. Um campo que pode compartilhar conosco alguns questionamentos sobre a realidade, mas cujas demandas são próprias de seu campo de atuação.

Defendemos que a educação e a aprendizagem históricas podem ser ferramentas na formação de guias de turismo que poderão atuar de forma a considerar e apresentar os atrativos de uma cidade a partir de questões que sejam historicamente relevantes, contribuindo também para o desenvolvimento de sua atividade profissional. Compreendendo que no decurso de sua ação a aprendizagem histórica pode ser um diferencial, os futuros guias de turismo poderão apresentar a cidade com base em diferentes camadas de temporalidade e considerando os diferentes elementos que a compõem.

Por fim, cabe destacar que não se buscou neste espaço esgotar o tema, apenas apresentar um conjunto de reflexões sobre o ensino de História em outros espaços que não apenas o da Educação Básica e Superior (em cursos de História). Buscou-se trazer ao debate a questão do professor de História que atua em outros campos e precisa pensar o seu fazer docente também levando 
em consideração a relação entre a História e o local onde atua. Para tanto, a contribuição da Teoria da História pode ser de grande valia.

\section{REFERÊNCIAS}

ALMEIDA, Adriana Mortara; VASCONCELLOS, Camilo de Melo. Por que visitar museus. In: BITTENCOURT, Circe (org.). O saber histórico na sala de aula. 12. ed. São Paulo: Contexto, 2013. p. 104-116.

ARAUJO, Valdei L. de. A aula como desafio à experiência da história. In: GONÇALVES, Marcia de A.; MONTEIRO, Ana Maria; REZNIK, Luís; ROCHA, Helenice (org.). Qual o valor da história hoje? Rio de Janeiro: Ed. FGV, 2012. v. 1, p. 66-77.

ASSUNÇÃO, Paulo de. Apresentação. In: ASSUNÇÃO, Paulo de. História do turismo no Brasil: entre os séculos XVI e XX - viagens, espaço e cultura. São Paulo: Manole, 2012. p. XIII-XXVI.

BOITEUX, Bayard do C.; WERNER, Mauricio. Introdução ao estudo do turismo. Rio de Janeiro: Elsevier, 2009.

CAMARGO, Haroldo. Fundamentos multidisciplinares do turismo: história. In: TRIGO, Luiz Gonzaga G. Turismo: como aprender, como ensinar. São Paulo: Ed. Senac-SP, 2000. p. 33-86.

CARVALHO, Ely B. de; COSTA, Jamerson de S. Ensino de História e meio ambiente: uma difícil aproximação. História \& Ensino, Londrina, v. 22, n. 2, p. 49-71, jul./dez. 2016.

CHIMENTI, Silvia; TAVARES, Adriana de M. Guia de turismo: o profissional e a profissão. São Paulo: Senac SP, 2007.

GONÇALVES, Márcia de A. História local: o reconhecimento da identidade pelo caminho da insignificância. In: MONTEIRO, Ana Maria et al. (org). Ensino de História. Rio de Janeiro: Mauad, 2007. p. 175-185.

GUIMARÃES, Selma. Didática e prática de ensino de História. 13. ed. revista e ampliada. São Paulo: Papirus, 2012.

GUMBRECHT, Hans U. Produção de Presença. Rio de Janeiro: Ed. PUC-RJ, 2010.

HARTOG, François. Regimes de historicidade: presentismo e experiências do tempo presente. Belo Horizonte: Autêntica, 2014.

HARTOG, François. Tempo e Patrimônio. Varia Historia, Belo Horizonte, v. 22, n. 36, p. 261-273, 2006.

HAYDT, Regia Celia C. Curso de Didática Geral. São Paulo: Ática, 2006.

KNAUSS, Paulo. O descobrimento do Brasil em escultura: imagens do civismo. Projeto História, São Paulo, n. 20, p. 175-192, abr. 2000. 
LIBÂNEO, José Carlos. Didática. São Paulo: Cortez, 1994.

LYRA, Cyro Correa. Documenta Histórica dos municípios do Estado do Rio de Janeiro. Rio de Janeiro: Documenta Histórica, 2006.

MENESES, José Newton C. História e Turismo Cultural. Belo Horizonte: Autêntica, 2006.

MENEZES, Leila M.; SILVA, Maria de Fátima. Ensinando história nas séries iniciais: alfabetizando o olhar. In: MONTEIRO, Ana Maria et al. (org.). Ensino de História. Rio de Janeiro: Mauad, 2007. p. 215-228.

ORIÁ, Ricardo. Memória e ensino de História. In: BITTENCOURT, Circe (org.). O saber histórico na sala de aula. 12. ed. São Paulo: Contexto, 2013. p. 128-148.

PERROTTA, Isabella. A construção de atrativos turísticos do Rio de Janeiro a partir de seus primeiros guias para viajantes. In: CASTRO, Celso; GUIMARÃES, Valéria; MAGALHAES, Aline (org.). História do turismo no Brasil. Rio de Janeiro: Ed. FGV, 2013. p. 37-52.

RÜSEN, Jörn. Jörn Rüsen e o ensino de história. (org.: M. A. Schmidt, I. Barca e E. Martins). Curitiba: Ed. UFPR, 2011.

SCHMIDT, Maria Auxiliadora; CAINELLI, Marlene. Ensinar história. São Paulo: Scipione, 2009.

WEHLING, Arno; WeHLING, Maria José. Formação do Brasil Colonial. Rio de Janeiro: Nova Fronteira, 1994.

\section{NOTA}

${ }^{1}$ Cabe destacar que "guia de turismo" é o profissional que atua na condução de grupos de turistas a atrativos em uma cidade, que possui formação e está devidamente autorizado pelo Ministério do Turismo; "guia turístico" consiste em livros ou manuais que apresentam determinada localidade. O surgimento dos "guias de turismo" pode ser visto como incentivador da prática do turismo.

Artigo recebido em 6 de março de 2019. Aprovado em 8 agosto de 2019. 